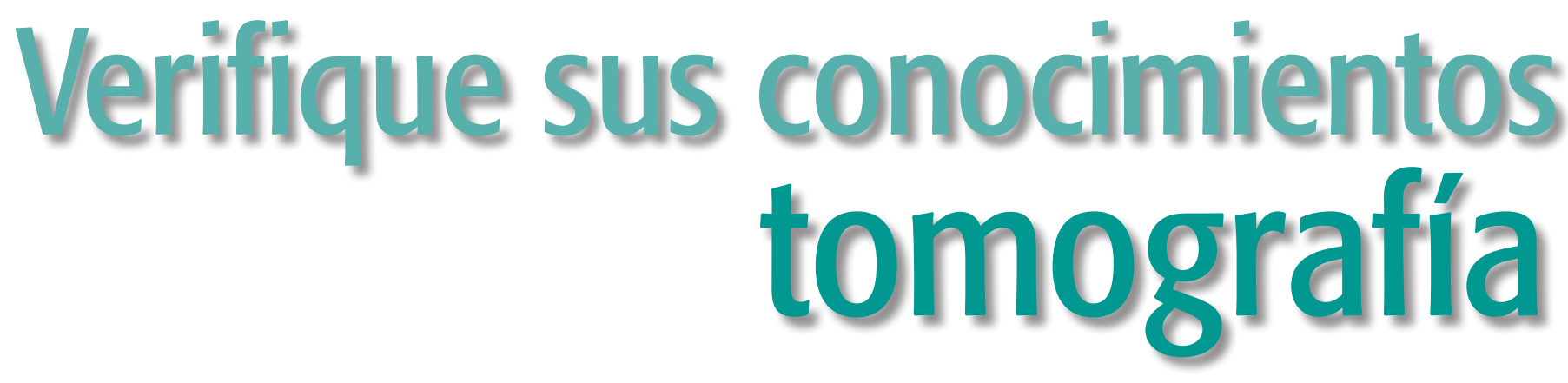

Jordi Galimany a e Ingrid Blancab

a Enfermero. Profesor de la E.U.E. de la Universidad de Barcelona. Barcelona. España.

${ }^{b}$ Enfermera. Unidad de Radiología. Hospital Sant Pau. Barcelona. España.

\title{
INTRODUCCIÓN
}

La presente entrega de la serie de Nursing sobre las pruebas complementarias está dedicada a la tomografía computarizada (TC).

La TC fue pensada inicialmente para explorar el encéfalo en profundidad, pero su capacidad diagnóstica ha caracterizado su evolución desde sus inicios a principios de la década de los setenta, cuando el ingeniero británico Sir Godfrey Newbold Hounsfield ideó el primer prototipo de TC. En la actualidad se utiliza para la exploración y estudio de prácticamente la totalidad de órganos y tejidos.

La TC se caracteriza por tener una elevada capacidad de discriminación en las estructuras anatómicas en función de su densidad. Esto permite diferenciar órganos, tejidos y sus lesiones, ofreciendo la posibilidad de obtener más información de la que mostraba la imagen radiológica convencional, que se caracterizaba por la obtención de una imagen general de la estructura a estudiar. En el caso de la TC, uno de los aspectos más destacados es la adquisición axial de la imagen, que permite estudiar porciones de anatomía. La capacidad de visión multiplanar de los nuevos equipos multicoronas, junto con la capacidad de diferenciar densidades, la convierten en una poderosa herramienta diagnóstica.

Desde el punto de vista de atención al paciente, la enfermera explica e informa sobre la dinámica de las exploraciones que, dadas las características de la TC, hacen imprescindible el conocimiento de las preparaciones y los cuidados durante y después de la técnica para que se resuelvan de manera eficaz y sin molestias para el paciente.

1 ¿Qué elemento/os diferenciador/es de la TC destacaría con respecto a la radiología convencional?

a. La posibilidad de obtener imágenes axiales de una estructura anatómica

b. La obtención de gran cantidad de imágenes de una estructura anatómica.

c. La capacidad de discriminar y diferenciar las estructuras anatómicas.

d. Todas las respuestas son correctas.

2. En general, la dinámica que usted debe conocer acerca de la realización de una TC es:

a. Son exploraciones poco complejas, de corta duración y que no causan dolor al paciente.

b. Es una técnica que utiliza radiación ionizante.

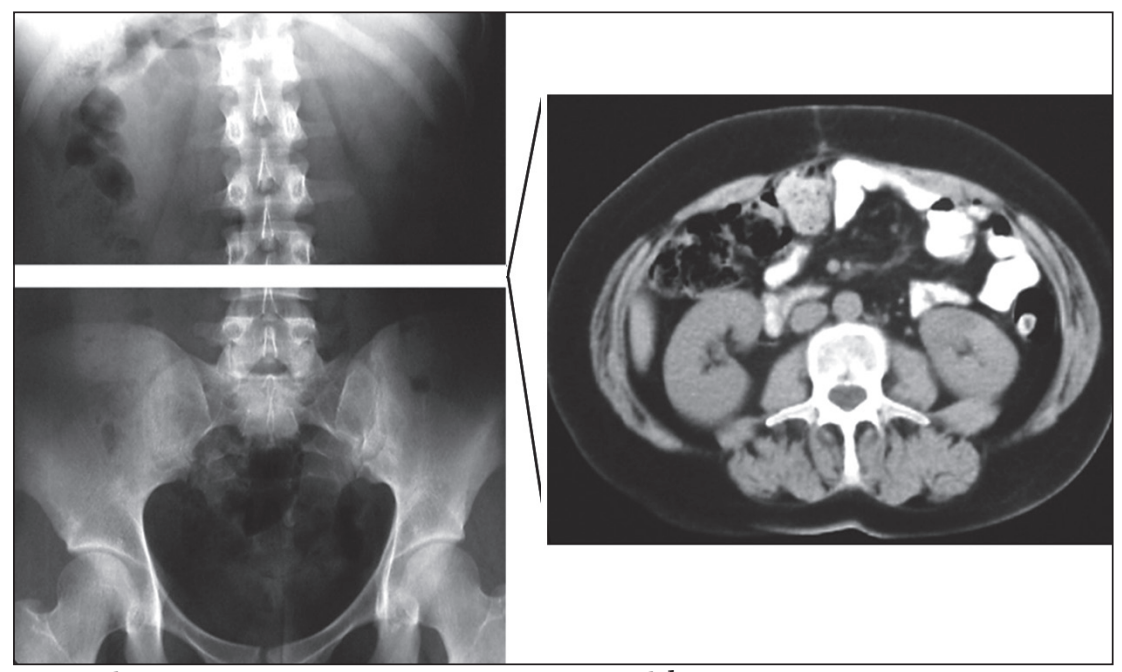

Figura 1 a
Figura 1 b 

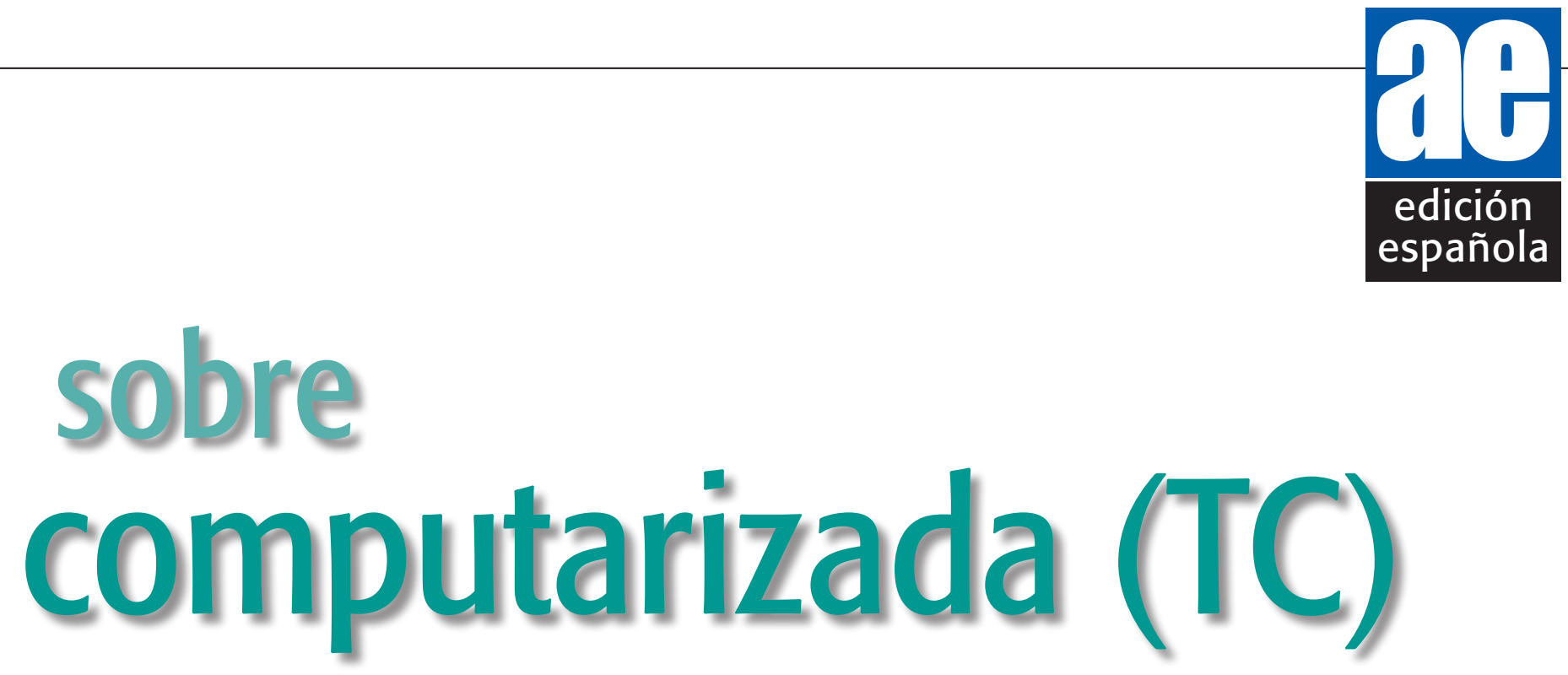

c. Es una técnica que dura unos $45 \mathrm{~min}$ y en la mayoría de los casos provoca claustrofobia.

d. Las respuestas a y b son correctas.

3. ¿Qué respuesta es la correcta respecto a las medidas de protección radiológica a tener en cuenta en las exploraciones con TC?

a. Es una técnica que irradia menos que las exploraciones radiológicas convencionales.

b. Es una técnica que irradia más que las exploraciones radiológicas convencionales.

c. Es una técnica que irradia igual que las exploraciones radiológicas convencionales.

d. No son necesarias medidas de protección, puesto que es una técnica diagnóstica que no irradia.

4. La preparación previa a tener en cuenta antes de realizar una TC consiste en:

a. Todas las exploraciones de TC precisan de un ayuno previo de 4-6 h.

b. La TC abdominal requiere de un ayuno de entre 6-8 h.

c. Únicamente precisan ayuno de entre 4-6 h las pruebas con contraste intravenoso (i.v.).

d. No se precisa preparación previa en ninguna prueba de TC.

5. En las exploraciones de TC se administra un contraste oral yodado con el fin de:

a. En la TC no se administra contraste oral en ningún caso. b. En la TC se administra contraste oral en algunos estudios abdominales.

c. En la TC se administra contraste oral en todas las exploraciones.

d. En la TC únicamente se administra contraste yodado i.v. en algunas exploraciones.

6. Con respecto al uso de contraste yodado i.v. en las exploraciones de TC:

a. Se puede administrar conjuntamente con el contraste oral.

b. Se puede administrar de forma manual, en forma de bolo o mediante bomba de perfusión.

c. La cantidad de contraste administrada oscila entre 80 y $150 \mathrm{ml}$, dependiendo del estudio.

d. Todas las respuestas son correctas.

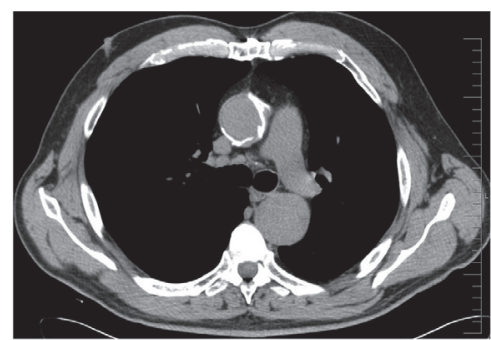

Figura 2 a

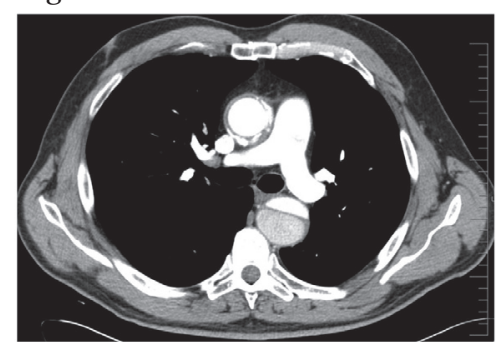

Figura 2 b
7. ¿En qué casos está contraindicada la realización de una $\mathrm{TC}$ ?

a. En pacientes con obesidad mórbida y niños de corta edad.

b. En pacientes en estado crítico.

c. En pacientes embarazadas.

d. Todas las respuestas son correctas.

8. Antes de realizar una TC hay que comprobar:

a. Si el paciente es portador de marcapasos o elementos metálicos.

b. Si el paciente tiene otras exploraciones programadas.

c. Las exploraciones previas del paciente.

d. Las respuestas b y c son correctas.
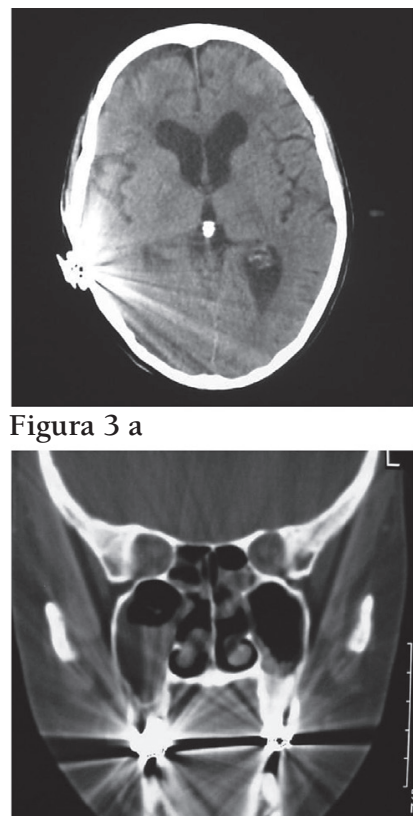

Figura $3 \mathrm{~b}$ 
9. Con respecto a la TC craneal, debemos saber que:

a. Es la técnica exploratoria de primera elección en el estudio del cráneo.

b. Es una prueba sencilla, que dura pocos minutos y, en condiciones normales, nada molesta para el paciente.

c. Permite discriminar alteraciones del encéfalo, como hemorragias o infartos.

d. Todas las respuestas son correctas.
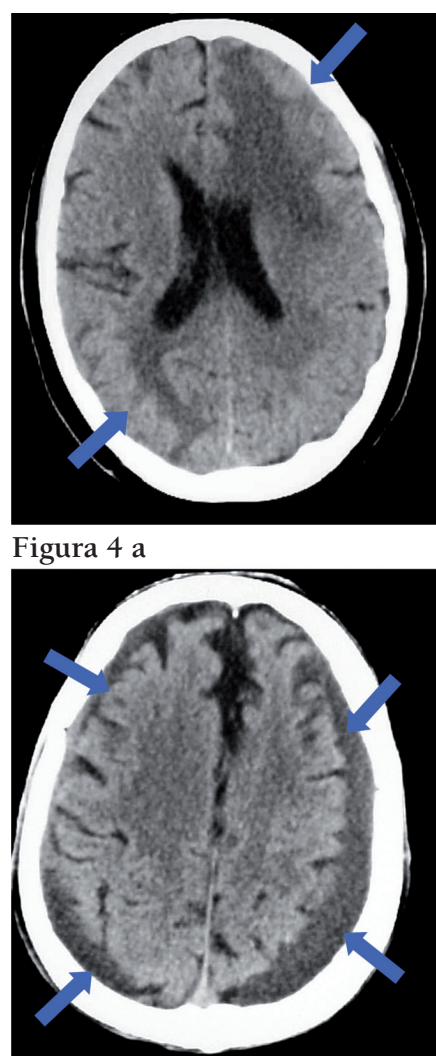

Figura 4 b

10. Con respecto a la TC abdominal, hay que tener en cuenta que:

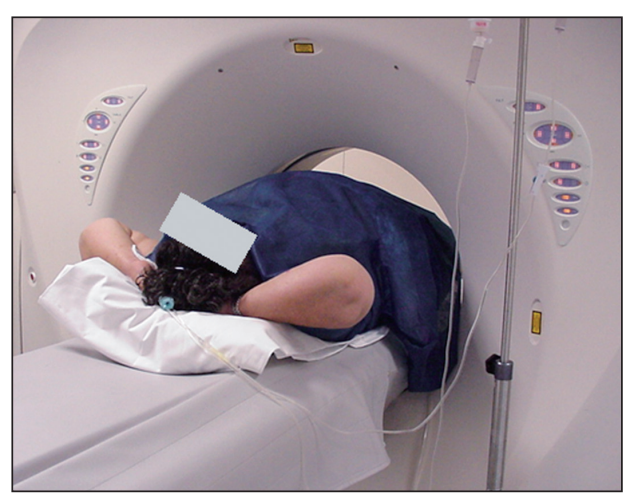

Figura 5 a. Es una exploración que suele requerir administración de contraste oral en la gran mayoría de casos.

b. Se precisa ayuno de 6-8 h por la posibilidad de administración de contraste intravenoso.

c. La técnica dura entre 15 y $30 \mathrm{~min}$, dependiendo de la estructura explorada y la patología.

d. Todas las respuestas son correctas.

\section{En el estudio de las estructuras} musculoesqueléticas mediante TC es cierto que:

a. La TC nunca está indicada en el estudio de estructuras musculares u óseas.

b. Está indicada en el estudio del parénquima óseo (estudio de hueso cortical y esponjoso).

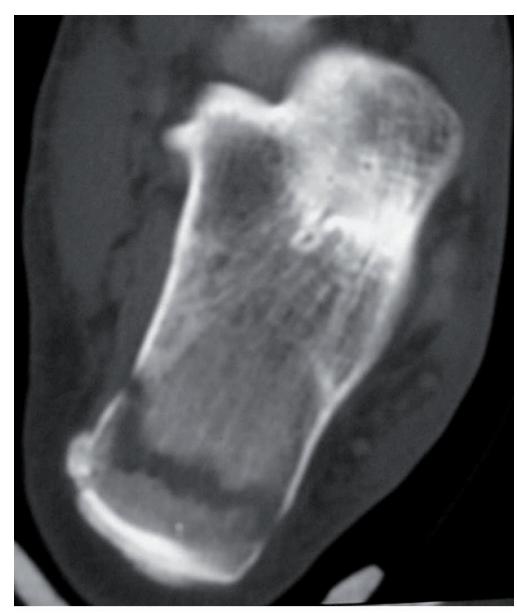

Figura 6 a

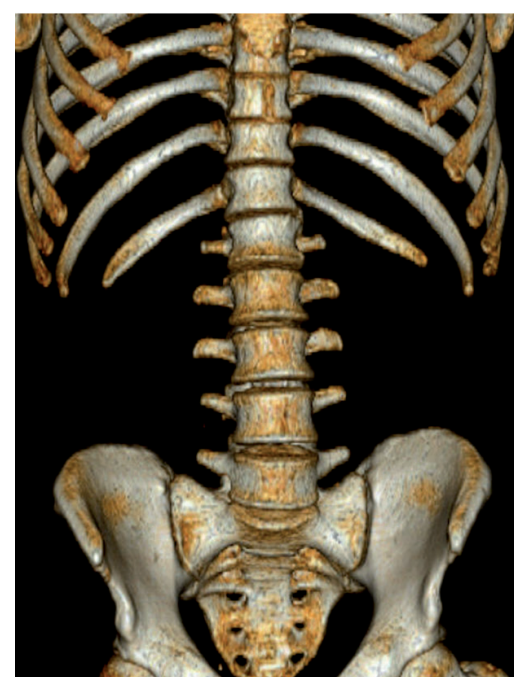

Figura $6 \mathrm{~b}$ c. Únicamente está indicada en estudios en tres dimensiones de fracturas óseas complejas.

d. Está indicada en el estudio de la médula espinal en las alteraciones de columna vertebral.

\section{2. ¿Existe la posibilidad de} utilizar la TC como mecanismo de localización y punción de lesiones?

a. La TC se utiliza como mecanismo de guía para punción de algunas lesiones.

b. La TC se utiliza como mecanismo de guía para realizar drenajes de abscesos y colecciones.

c. La TC no está indicada en este tipo de procedimientos.

d. Las respuestas a y b son correctas.

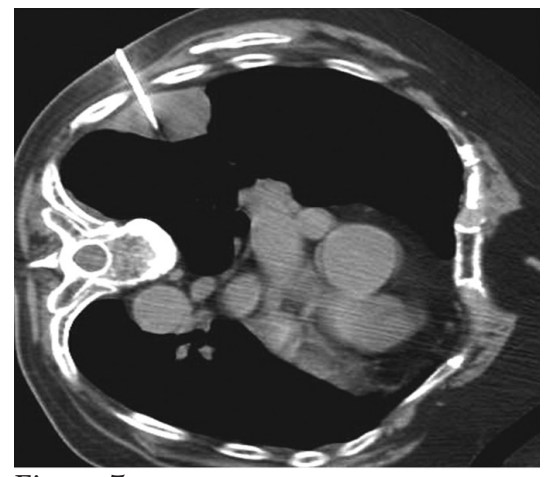

Figura 7 a

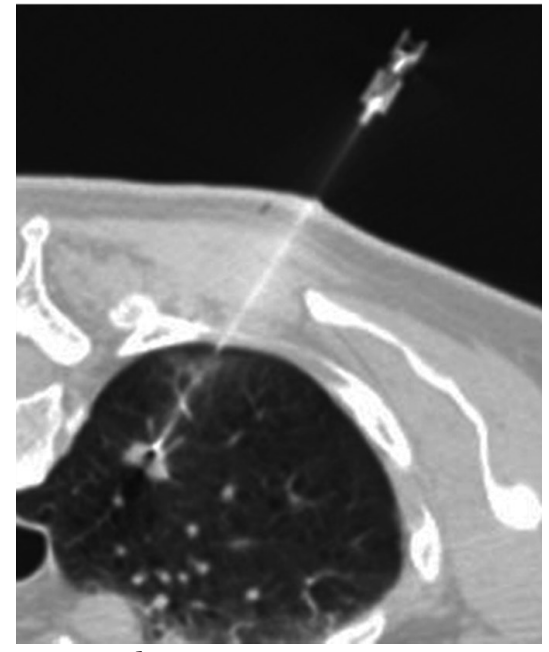

Figura $7 \mathrm{~b}$

\section{Indique qué cuidados de} enfermería se deben tener en cuenta después de la realización de una TC:

a. No se precisan cuidados de enfermería posteriores a la realización de la TC. 
b. Hay que prestar atención a posibles reacciones adversas en caso de haber administrado contraste yodado i.v.

c. Se debe controlar la permeabilidad de la vía periférica utilizada para administrar el contraste i.v.

d. Las respuestas b y c son correctas.

14. Según su criterio, ¿en cuál de los siguientes casos está indicada la realización de una $\mathrm{TC}$ ?

a. La TC es una técnica indicada en el estudio de nódulo pulmonar solitario.

b. La TC está indicada para estudios fetales.

c. La TC es la técnica de primera elección en el estudio del tórax.

d. La TC está indicada en el tratamiento de lesiones vasculares.

15. Respecto a la TC y sus posibles aplicaciones, debemos saber que:

a. Se puede estudiar el interior del intestino de manera no invasiva mediante una simulación en tres dimensiones (colonoscopia virtual).

b. La TC es una herramienta muy útil en pacientes politraumáticos.

c. La TC de última generación permite estudiar el corazón y las arterias coronarias.

d. Todas las respuestas son ciertas.

\section{Respuestas}

1. d. La diferencia más relevante de la TC con respecto a las técnicas radiológicas estudiadas hasta el momento en la serie de Nursing sobre las pruebas complementarias es su capacidad a la hora de diferenciar estructuras anatómicas o lesiones en función de su densidad radiológica. En la radiología convencional existe la posibilidad de identificar diferencias en estructuras anatómicas que posean una diferencia de densidad elevada, por ejemplo entre el hueso, las partes blandas o el aire, pero es imposible diferenciar estructuras o cambios en zonas anatómicas con densidad muy similar, mientras que la TC permite diferenciar estas estructuras.

También es relevante el tipo de imagen diagnóstica obtenida. En la imagen $1 b$ se muestra un corte axial a nivel abdominal obtenido mediante TC. En este caso se obtiene una imagen axial de una sección de tejido más o menos gruesa en función del estudio. Este tipo de imagen hace que la anatomía radiológica sea distinta respecto a la vista hasta ahora (imagen la correspondiente a una radiografía convencional de abdomen). La amplia tonalidad de grises que se muestra en las exploraciones de TC sigue dependiendo de la densidad del tejido atravesado por la radiación y la mayor o menor absorción de ésta en el tejido. Así, y en general, las estructuras más densas (metal, contraste, hueso) se visualizaran de color blanco, mientras que las estructuras menos densas (grasa y aire) tienden al negro en la imagen. La cantidad de imágenes obtenidas es mucho mayor que en la exploración convencional, compuesta normalmente por dos imágenes para situar en el espacio cualquier estructura. La TC puede obtener hasta centenares de imágenes del abdomen o del tórax, dependiendo del grosor de corte. Estas imágenes axiales se pueden presentar en formato de placas radiográficas, aunque la tendencia actual es utilizar dispositivos digitales, dada la cantidad de imágenes e información que proporciona la exploración.

2. d. Las exploraciones de TC son pruebas poco complejas, no son invasivas (pese a la administración de contraste i.v.) y por tanto en la mayoría de los casos no causan dolor al paciente, salvo en procedimientos muy concretos (punciones, drenajes, etc.), que se analizan más adelante. El paciente permanece tendido en decúbito supino en una mesa dura en la práctica totalidad de las técnicas. Por lo que respecta a los tiempos de exploración, van desde los 5-10 min de la TC craneal hasta los 20-30 min de las exploraciones de abdomen, aunque esto puede variar ligeramente en función del protocolo de cada centro y, sobre todo, en función del aparato de TC. Otro aspecto para tener en cuenta es que se pueden realizar reconstrucciones, mediciones u otras técnicas de imagen para llegar a una conclusión diagnóstica. Estos procedimientos se realizan de forma diferida, por lo que el paciente, una vez hecha la adquisición de las imágenes, puede abandonar la mesa de exploración. El otro elemento destacado para tener en cuenta es que la obtención de la imagen se basa en la radiación ionizante. En la pregunta 3 se describen las características concretas en relación a la TC.

En la mayoría de los casos la TC no causa sensación de claustrofobia en los pacientes, puesto que la máquina tiene una obertura ancha y corta en la zona de adquisición de la imagen (gantry).

3. b. Tal como se ha indicado, la obtención de la imagen de TC se basa en la radiación ionizante. Esto significa que se deben tomar en consideración las medidas descritas en la entrega de Nursing sobre las pruebas complementarias dedicada a la radioprotección. Las medidas de protección básica son el plomado de las salas, el uso de vestuario plomado y mantener el máximo de distancia del foco de emisión de radiación en caso de ser necesario permanecer en la sala.

Existen ciertas peculiaridades de la TC con respecto a la radiología convencional. Las dosis de radiación en los tejidos y estructuras anatómicas estudiadas mediante TC son más elevadas con respecto a la radiología convencional. En general, puesto que el cálculo concreto depende de múltiples factores, como el peso de la persona, el tipo de aparato de emisión y la zona anatómica irradiada, la dosis puede ser hasta 100 veces más elevada. Sin embargo, hay que destacar que las últimas generaciones de TC incorporan mecanismos de control de dosis que pueden ser muy útiles, sobre todo en los pacientes pediátricos sometidos a este tipo de exploraciones. Como siempre, la correcta indicación de la exploración garantiza la efectividad de la técnica y la seguridad e integridad del paciente, y permite la obtención de valiosa información diagnóstica.

4. c. La preparación previa a una TC depende de la exploración en concreto. En general la preparación tiene que ver con la administración de contraste yodado i.v. Si la técnica comporta su administración, el paciente debe permanecer en ayuno durante 
unas 4-6 h (en el caso de pacientes diabéticos, 4 h). Esta preparación obedece a la posibilidad de que, al inyectar el contraste, se produzcan náuseas o mareos que podrían provocar vómito y broncoaspiración del contenido gástrico, puesto que el paciente está tendido boca arriba. Además del contraste i.v., se puede administrar el contraste por vía oral.

En las exploraciones de cráneo, musculoesqueléticas, de tórax o de abdomen en las que no está previsto administrar contraste, no se precisa ayuno.

\section{5. b. El objetivo del contraste} yodado oral es la opacificación del tubo digestivo para descartar y diferenciar esta estructura anatómica. El contraste oral es una dilución en aproximadamente un litro de agua que el paciente se toma una media hora antes de la exploración.

El contraste oral se puede utilizar conjuntamente en la prueba con el contraste i.v. Éste es el caso típico de las exploraciones abdominales en las que coexisten normalmente ambos contrastes.

Excepcionalmente este contraste diluido puede administrarse por vía rectal para facilitar el llenado de la ampolla rectal y del recto cuando ésta es la zona de interés. Las reacciones al contraste oral son muy raras.

En ningún caso se administra contraste baritado en las exploraciones de TC. Si se ha realizado recientemente una exploración con bario, se pueden producir dificultades en la visualización de las imágenes, puesto que el bario puede retenerse en el intestino y generar una alta densidad de contraste (blanco intenso) que provoca artefactos al visualizar dichas estructuras.

6. d. El uso de contraste yodado i.v. tiene diversas indicaciones en la TC. Por un lado sirve para visualizar las estructuras venosas y arteriales, facilitando su diferenciación en los estudios debido a la densidad (color blanco intenso) con que se muestran en las imágenes de TC. Por otro lado, el contraste sirve para diferenciar los distintos tipos de tumores de las vísceras sólidas, en función de su comportamiento dinámico.
Como aspectos destacados para los cuidados al paciente hay que resaltar, por un lado, la cantidad de contraste que se administra (entre $80-150 \mathrm{ml}$ ) y, por otro, la velocidad de perfusión a la que se administra (entre 1,5-5 ml/s). También la forma de administrarlo puede variar según los casos. Se puede administrar en forma de bolo manual o mediante una bomba de inyección de contraste con el fin de coordinar la perfusión con la adquisición de la imagen en el momento oportuno, para conseguir la concentración de contraste adecuado en la zona de interés.

La figura 2 muestra dos imágenes correspondientes al mismo corte anatómico en la zona media del mediastino, con densidad negra correspondiente al parénquima pulmonar, con densidad gris en la zona del mediastino y con densidad hueso en las zonas que corresponden a la vértebra, las escápulas, el esternón, las costillas y una importante calcificación en las paredes de la arteria aorta. La imagen de la figura 2 a no contiene contraste en los vasos de esta zona, mientras que la figura $2 \mathrm{~b}$ muestra la densidad de blanco intenso en los vasos correspondiente al contraste yodado. En esta imagen se puede apreciar una disección aórtica. Se corresponde a la línea hipodensa (negra) que divide la luz de la aorta torácica descendente (que se encuentra cercana al cuerpo vertebral). Este diagnóstico vital no sería posible sin la administración de contraste i.v.

7. c. La exploración mediante TC está contraindicada en pacientes embarazadas para evitar la irradiación del feto. Además hay que valorar antecedentes de alergia al contraste yodado y, en tal caso, valorar las alternativas diagnósticas a la TC.

Los pacientes que no puedan permanecer en decúbito supino durante el tiempo que dura la exploración (pacientes con dificultad respiratoria, con problemas de columna vertebral o de avanzada edad) pueden plantear dificultades, y hay que valorar si la exploración podrá realizarse con garantías de seguridad para el paciente.

Si bien no está contraindicada en niños, como norma habitual se intenta realizar con menor dosis de radiación.
Se puede realizar en pacientes muy obesos o en pacientes críticos, si bien sus condiciones clínicas y físicas pueden dificultar la exploración.

8. d. Aunque la presencia de materiales metálicos no contraindica la realización de la TC, éstos pueden dificultar el correcto visionado de la imagen. Como se muestra en las imágenes de la figura 3, la presencia de materiales metálicos provoca una imagen clásica denominada imagen "en estrella" por la alta densidad del metal. En la figura 3a se observa un corte axial en la zona media del encéfalo, con un elemento metálico en la calota que dificulta su visualización. En la figura 3b se observa un corte coronal en el macizo facial y se identifica una imagen artefactual "en estrella" bilateral que corresponde a dos empastes dentarios.

En relación a la programación de la TC en pacientes con otras exploraciones, se debe considerar el orden de realización de las pruebas, sobre todo si se han realizado exploraciones con bario, que puede dificultar la imagen de TC. Para ello se intenta realizarlas después o se espera un tiempo prudencial para asegurar la eliminación máxima del bario. Por otra parte, es necesario que el paciente aporte los estudios previos de que disponga, ya que en muchos casos se hacen estudios comparativos para determinar la evolución de procesos patológicos o en fase de curación o seguimiento.

9. d. La exploración craneal mediante TC es una de las solicitudes más habituales, dado que es un procedimiento sencillo, que dura pocos minutos y nada molesto para el paciente.

Está indicada en la valoración de accidente vascular cerebral, traumatismos craneoencefálicos y sospecha de procesos tumorales.

En este caso la indicación de contraste es en los estudios de los vasos intracraneales, lesiones focales, metástasis, tumores y abscesos, entre otras.

En la figura 4a, el corte axial en la parte media del encéfalo muestra una asimetría del lóbulo frontal izquierdo que aparece hipodenso, lo que indica un proceso isquémico cerebral. En la figura 
4b se observa un corte igualmente axial del cerebro que muestra colecciones subdurales bilaterales

10. d. En la mayoría de los casos, la técnica de TC abdominal requiere la administración de contraste oral, excepto en estudios del hígado, del páncreas, del bazo, de los riñones, de la vía urinaria, de las suprarrenales o de la aorta, en los que no es necesario. Por lo que respecta a la administración de contraste i.v. (y la consiguiente necesidad de ayuno), está indicada por el radiólogo a cargo de la exploración o bien recogido en los protocolos de estudio.

La posición del paciente en la mesa de exploración es la que se observa en la imagen de la figura 5: decúbito supino con los brazos separados al máximo de la zona abdominal. En condiciones de movilidad normal del paciente se desplazan como se muestra en la imagen. Si eso es imposible por estar el paciente inconsciente o por algún tipo de lesión que lo impida, la técnica puede realizarse con los brazos a lo largo del cuerpo.

Durante la adquisición de la imagen el paciente debe permanecer en apnea o respirando suavemente, para evitar artefactos de movimiento en las imágenes.

Por lo que respecta al tiempo de exploración, puede variar en función de la indicación de la técnica. Si es un estudio sin contaste, dura pocos minutos, mientras que si se realiza con contraste en diferentes fases, se puede dilatar hasta aproximadamente $30 \mathrm{~min}$, dependiendo del caso concreto.

11. b. La TC está indicada en el estudio de estructuras óseas, en las que diferencia el hueso cortical del hueso esponjoso, más allá de poder identificar fracturas o pequeñas fisuras difícilmente identificables con radiología convencional (figura 6a). También es útil en el estudio de las partes adyacentes al hueso y las articulaciones.

La TC de huesos y articulaciones se realiza para estudios tridimensionales (figura 6b) de fracturas óseas complejas, como preoperatorio o como seguimiento de ellas, dada la capacidad de mostrar, de manera virtual, las características de la lesión mediante diferentes planos anatómicos además de la imagen en tres dimensiones, que permite obtener una imagen muy cercana a la realidad.

Los estudios de TC de la columna vertebral tienen como objetivo estudiar los cuerpos vertebrales y los espacios intervertebrales. La médula se estudia mediante resonancia magnética.

12. d. La TC es una modalidad diagnóstica que, como se ha visto, permite diferenciar y caracterizar lesiones y alteraciones de manera concreta.

En algunos casos, y según el tipo de lesión (masa, absceso, colección, etc.), puede ser preciso, por un lado, extraer una muestra de tejido anatómico de dicha lesión para su estudio anatomopatológico, y por otro puede ser necesario drenar un absceso. En este caso la ventaja es que el paciente no necesita ser intervenido con cirugía abierta.

La TC ofrece una información precisa sobre el trayecto a seguir para que la punción sea efectiva sin lesionar otras estructuras vecinas. Existen algunas estructuras anatómicas que se deben evitar puncionar por el riesgo de lesiones (vasos arteriales o venosos, vísceras huecas, bazo).

Tal como se muestra en las imágenes de la figura 7, estas punciones pueden realizarse en diferentes estructuras anatómicas. En la figura 7a se observa una punción de una masa pleural que no interesa al pulmón subyacente. La imagen de la figura $7 \mathrm{~b}$ muestra la punción dirigida y selectiva de una lesión parenquimatosa pulmonar.

13. d. Los cuidados de enfermería posteriores a la realización de la TC están relacionados con la administración de contraste i.v. En algún caso se puede producir extravasación de contraste durante la técnica, que provocaría que éste se alojara en el espacio subcutáneo con el consiguiente dolor, irritación e incomodidad para el paciente. El tratamiento en estos casos consiste en favorecer la reabsorción del contraste con compresión o, en algún caso, drenando el contraste de forma quirúrgica.

En pacientes portadores de vías i.v. periféricas o centrales hay que lavar la vía después de la inyección para asegurar su permeabilidad, pues el contraste yodado es denso y puede obstruir la vía.
Desde el punto de vista de cuidados, hay que valorar también la aparición tardía de signos y síntomas de alergia y, en su caso, tomar medidas.

Por otra parte, en las exploraciones más invasivas, como punciones o localizaciones para colocar sistemas de drenaje de colecciones, tanto la preparación como los cuidados posteriores dependen del tipo de procedimiento y también de la zona anatómica afectada. En general, previamente se deben realizar determinaciones analíticas de coagulación y valorar la posibilidad de administración de tratamiento antibiótico, además del preceptivo consentimiento informado.

Posteriormente a la técnica se debe observar el punto de punción por la posible aparición de hematomas, dolor local o fiebre.

14. a. La TC está indicada en el estudio del nódulo pulmonar solitario, aunque para estudio del tórax en general no se considera la técnica de primera elección, puesto que la radiografía de tórax aporta, en primera instancia, mucha información de manera rápida y sin excesiva irradiación del paciente.

En las exploraciones de TC torácica no se administra contraste oral, aunque sí contraste i.v. en función de la patología por la que se realiza, generalmente en el estudio de los grandes vasos mediastínicos.

La TC torácica dura pocos minutos y el paciente permanece en decúbito supino, con los brazos retirados hacia la cabeza, fuera de la zona anatómica del tórax.

En la exploración torácica el paciente debe intentar inspirar profundamente y mantener la respiración durante la adquisición de la imagen, evitando así artefactos de movimiento.

La TC no está indicada en estudios fetales, puesto que se irradia al feto.

Pese a que las máquinas de TC de última generación proporcionan imágenes muy precisas y útiles de las estructuras vasculares, si además de precisar diagnóstico se requiere tratamiento de lesiones vasculares, el procedimiento vascular intervencionista es la técnica de imagen, como se estudió en la entrega de Nursing correspondiente a las pruebas complementarias. 
15. d. Actualmente se puede estudiar el interior del intestino de manera no invasiva mediante una simulación en tridimensional con la reconstrucción a partir de la información que la TC hace de una zona anatómica. Esta simulación también se puede hacer en otras estructuras huecas, como por ejemplo la vía aérea o grandes vasos arteriales. Estas técnicas se denominan colonoscopía y broncoscopia virtual, y navegación intravascular en el caso de la aorta. Las ventajas para el paciente son obvias, puesto que no es preciso introducir el endoscopio para hacer el estudio. Además, la precisión diagnóstica es prácticamente la misma, aunque presenta la limitación de que, lógicamente, no permite obtener muestras o biopsias, así como tampoco permite realizar procedimientos terapéuticos intraluminales.

El estudio del corazón y de las arterias coronarias mediante TC es otra de las posibilidades diagnósticas de última incorporación en las posibilidades de la TC como modalidad diagnóstica. En este caso, los cuidados previos a la técnica no difieren de los habituales, únicamente se administra, bajo prescripción facultativa, un bradicardizante justo antes del momento de la exploración.

En la actualidad la TC destaca por su capacidad de obtener más número de imágenes (y por tanto más información) de manera más rápida. Esta característica es importante para el paciente, puesto que las exploraciones duran menos tiempo y se pueden realizar estudios más complejos de manera más rápida y sencilla sin que ello suponga una dosis significativamente mayor de radiación. Éste es un elemento muy relevante en el caso, por ejemplo, de pacientes politraumatizados, críticos, agitados o en el caso de niños. 벙

\section{Bibliografía general}

Agukera F, Fernández E, García E, Moriana J, Granero J, Aguilera G. Drenaje percutáneo de abscesos dirigido por TAC. Rev ROL Enf. 2001;24:12-6

Brateman L. Radiation safety considerations for diagnostic radiology personnel. Radiographics. 1999;19:1037-55

Brenner DJ, Hall EJ. Computed tomography, an increasing source of radiation exposure. $\mathrm{N}$ Engl J Med. 2007;357(22):2277-84
Eisenberg RL. Diagnóstico por la imagen: patrones de diagnóstico diferencial. 2. ${ }^{a}$ ed. Madrid: Marvan 1995

Eisenberg RL, Dennis C. Radiología patológica Madrid: Mosby Yearbook; 1992.

Fleckenstein P, Tranum-Jensen J. Bases anatómicas del diagnóstico por la imagen. 2. ${ }^{a}$ ed. Madrid: Elsevier; 2002

Gerhardt P, Frommhold W. Atlas de correlaciones anatómicas en TAC y RMN. Barcelona: Salvat; 1989.

González J, Vara J, Vázquez J. Tomografía computerizada. Madrid: Paraninfo; 1992.

Johnson K, Rowberg A. Tomografía computerizada. En: Ballinger P, editor. MERRILL. Atlas de posiciones radiológicas y procedimientos radiológicos. Barcelona: Masson-Salvat; 1993. p. 249-63.

Martí J, Pallardo Y. Medios de contraste en radiología. Madrid: Médica Panamericana; 2008.

Manchón A. Tomografía computerizada: nociones básicas. 2. ${ }^{a}$ ed. Barcelona: Salvat; 1982.

Pedrosa CS, Casanova R. Diagnóstico por la imagen: compendio de radiología clínica. 14. a ed. Madrid: Mc Graw-Hill Interamericana; 2001.

Correspondencia: Jordi Galimany Masclans. Departament d'Infermeria de Salut Pública, Salut Mental i Materno-Infantil.

Campus de Bellvitge. Pavelló de Govern, 3a planta. C/ Feixa Llarga s/n.

08907 L'Hospitalet de Llobregat. Barcelona. España. Correo electrónico: jordigalimany@ub.edu

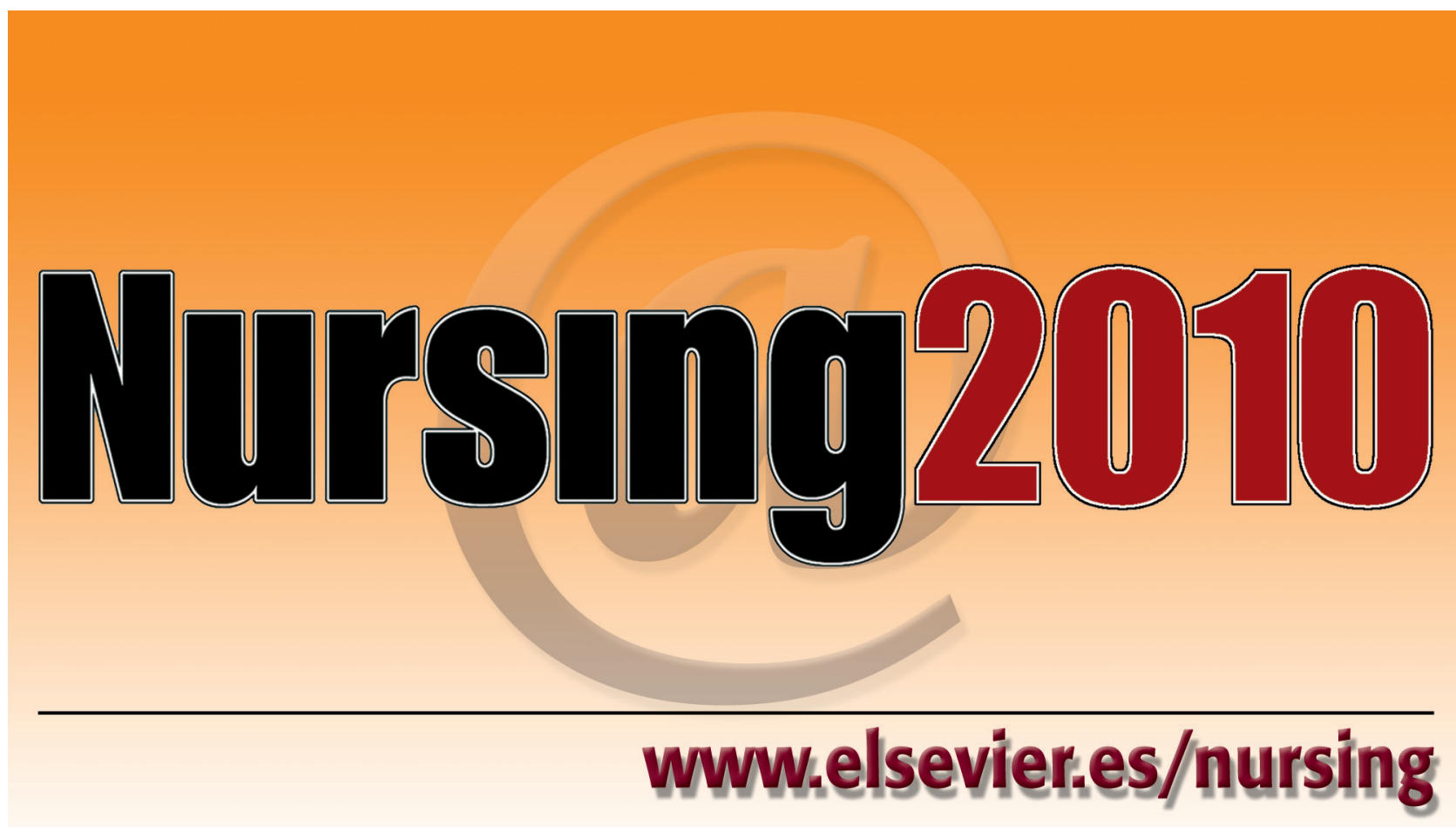

